\title{
Autonomia outorgada e Relação COM O TRABALHO: LIBERDADE E RESISTÊNCIA NO TRABALHO NA INDÚSTRIA DE PROCESSO
}

CINARA L. ROSENFIELD*

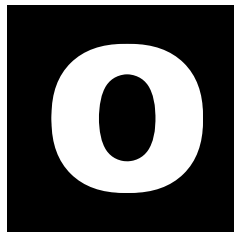

presente estudo busca investigar os efeitos das mudanças organizacionais recentes sobre a relação com o trabalho entre operadores da indústria de produção. Essas mudanças apontam para exigências de mobilização subjetiva dos trabalhadores, a fim de atingir a correta execução de suas responsabilidades, o que vem a constituir um quadro de autonomia outorgada - a autonomia é outorgada na medida em que ela é "concedida" aos trabalhadores, mas se constitui, ao mesmo tempo, em uma ordem a ser obedecida. A investigação se dá através de duas pesquisas empíricas realizadas na indústria de processo, uma vez que esta constitui o exemplo mais completo das novas organizações do trabalho onde a automatização e a própria natureza da atividade exigem um trabalho predominantemente autônomo de controle e supervisão. A primeira concerne uma pesquisa junto à indústria de processo (química), na França (Péage de Roussillon) e no Brasil (Paulínia-SP), nos anos de 1993-4. Este estudo compreende 200 entrevistas semi-diretivas nos dois países e resulta em uma tipologia comparativa da relação com o trabalho em um contexto de autonomia outor-

* Professora do Departamento de Sociologia e do Programa de Pós-Graduação em Sociologia da Universidade Federal do Rio Grande do Sul. 
gada. A segunda refere-se igualmente a uma investigação na indústria de processo (petroquímica) no Pólo Petroquímico de Triunfo (RS), nos anos de 2000-1, junto a 40 trabalhadores, seguindo a mesma metodologia utilizada anteriormente. O objetivo deste estudo é testar a tipologia construída quando da pesquisa anterior, ao menos em relação aos modelos encontrados entre os trabalhadores brasileiros. O objeto de estudo de ambas as pesquisas é o sujeito no trabalho: quais são os efeitos induzidos por um processo de autonomia outorgada sobre as relações dos trabalhadores industriais com seu próprio trabalho.

O contexto social em que se associam desemprego estrutural, desemprego tecnológico e enfraquecimento das formas de proteção social atinge diretamente o grupo de trabalhadores industriais que deve, a partir da década de 90, responder a novas exigências de produção pautadas na qualidade e na competitividade e, ainda, fazê-lo em meio a um cenário de perda da segurança do trabalho e da proteção da legislação trabalhista. A flexibilização da força de trabalho - propagandeada como a condição imprescindível à adaptação da produção industrial aos novos cânones da competitividade mundial - significa ampla margem de liberdade para o capital, insegurança e um surplus de trabalho para os de trabalhadores.

A antiga organização do trabalho taylorista ou fordista renova-se para tornar-se capaz de dar respostas a um outro tipo de exigência: para garantir qualidade e competitividade, agora em escala inédita, o trabalho do operário industrial deve integrar a compreensão da tarefa, de maneira a possibilitar um trabalho de concertação e de troca de informações e saberes não só no momento de execução da tarefa, mas também no de sua concepção. O trabalhador é impelido a participar da melhoria da produção e a dispor de seu savoir faire e de sua capacidade pessoal de tomar iniciativas. A disponibilização dessas capacidades implica que o sujeito seja autônomo, que tome iniciativas e se implique pessoalmente na execução de seu trabalho. A introdução do trabalho imaterial - cujo produto 
é consumido no momento mesmo de sua produção - supõe capacidades de comunicação, compreensão, cooperação e criação por parte da força de trabalho, mas que não podem ser comandadas: podem ser requeridas, mas sua disponibilização depende do investimento pessoal no trabalho. Esta é a nova face da dominação do capital: é mister que o trabalhador se identifique pessoalmente, que se mobilize subjetivamente, que lance mão de suas capacidades psíquicas e relacionais para bem executar seu trabaIho. Há uma mudança na natureza do trabalho - chamada de "enriquecimento" da natureza e do conteúdo do trabalho - mas este mesmo trabaIho "rico" tornou-se raro. O trabalho mantém suas funções de elemento maior de inserção social, de condição para a obtenção de direitos sociais, de meio para a preservação da auto-estima e do reconhecimento social, mas não é mais acessível a todos os indivíduos. O desemprego geral - e o desemprego industrial especificamente - e a complexificação do trabalho operário são as duas faces de um processo global do capitalismo em sua fase atual.

Diante deste quadro, a questão colocada pelo presente estudo é quais são os efeitos desse processo sobre as relações que os trabalhadores industriais estabelecem com seu próprio trabalho, no interior mesmo da situação de trabalho. É possível supor que um enriquecimento da natureza e do conteúdo do trabalho seja um ganho para eles, uma vez que a pessoa mesmo do trabalhador é mobilizada para a execução da tarefa. Ao invés de tarefas repetitivas e monótonas, o trabalho industrial tornou-se mais complexo e instigante. E mais ainda, há uma maior leveza hierárquica e uma liberalização da situação de trabalho em substituição às antigas organizações rígidas e autoritárias. O cenário poderia ser caracterizado como de otimismo já que as mudanças apontam a priori para um trabalho mais interessante e uma democratização das relações de trabalho. O objetivo deste estudo é justamente investigar como os trabalhadores vivenciam estas mudanças e quais seus efeitos sobre sua relação com o próprio trabalho. Há ganhos para os 
trabalhadores? E quais são eles? Há perdas? E quais são elas?

A pesquisa empírica se apóia sobre os seguintes eixos: o primeiro é consagrado às entrevistas semidiretivas nas quais se privilegiam a palavra dos trabalhadores, suas vivências e os aportes de um processo de elaboração que se instaura na situação de entrevista, através da escuta e da interferência do pesquisador. O segundo consiste em observar o processo de trabalho, o clima no interior da situação de trabalho, em travar contatos mais informais, em conhecer o cotidiano do trabalho. O terceiro se dá em duas partes e se refere à restituição (feedback), em pequenos grupos de trabalhadores entrevistados, das regularidades constatadas nas entrevistas e, após, a mesma restituição para a direção da empresa. As reuniões com os trabalhadores entrevistados servem, simultaneamente, para validar os resultados preliminares (e, assim, obter o acordo dos trabalhadores entrevistados quanto ao conteúdo que será apresentado à direção da empresa) e para projetar os entrevistados e os resultados em um processo mais coletivo. O quarto eixo, referente somente à comparação internacional, remete à coleta de dados sociais dos países envolvidos na pesquisa, a fim de enquadrar e contextualizar aquilo que diz respeito às implicações sociais da relação com o trabalho. No caso da segunda pesquisa, esses dados limitam-se a enquadrar e contextualizar a própria empresa.

Os quatro eixos da pesquisa empírica remetem às duas linhas teóricas deste estudo: a relação com o trabalho em sua dimensão individual e a relação com o trabalho em sua dimensão social. O homem se constrói como pessoa segundo diferentes modelos do mundo social e ainda acede a uma parcela de autonomia e originalidade, de maneira a tornar-se, simultaneamente, um ser social e autônomo, coletivo e particular, igual e único. A relação com o trabalho é uma, entre outras, expressão desta associação entre o social - as condições objetivas de trabalho, a organização do trabalho de tipo autônomo como resposta a uma exigência de 
flexibilização, a empresa capitalista e o objetivo sempre presente de produzir riquezas, etc. - e individual - como o homem, este homem, vive sua inserção no trabalho, este trabalho. A dimensão social da relação com o trabalho confere à ação individual um sentido, e, ao mesmo tempo, o sentido que o indivíduo confere à sua ação em relação a um contexto mais geral remete à sociedade envolvente.

Se procuramos compreender a relação com o trabalho, desenvolvida por indivíduos inseridos em organizações mais autônomas, o indivíduo particular deve ser a fonte primeira da pesquisa, a fim de reconhecer regularidades capazes de definir um tipo de relação com o trabalho característico de um "modelo" de indivíduo. Trata-se de ultrapassar os dados individuais, de maneira a utilizá-los para compreender uma atitude mais ou menos geral no trabalho. Uma tipologia de indivíduos no trabalho foi, então, proposta, a fim de desvendar as diferentes atitudes vividas na situação específica de trabalho, cuja principal característica é a demanda de um trabalho autônomo por parte do trabalhador. A passagem do individual ao social marcaria, assim, a passagem do particular ao geral, onde esses níveis servem simultaneamente de base de compreensão para a realidade observada. É preciso ser claro: não é simplesmente o social que confere um sentido ao vivido, mas o vivido existe, ao mesmo tempo, em si - ou seja, mais estreitamente ligado à organização do trabalho compreendida como modo operatório, relações sociais de produção e relação com a empresa e em um contexto macrosocial onde ele apresenta determinações de ordem socioculturais e político-econômicas. A vivência é ela mesma um elemento de compreensão da relação com o trabalho, mas submetida, ela também, às grandes determinações socioculturais. Como afirma Manuel Castels (1998), as culturas e as identidades coletivas são estruturadas por relações historicamente determinadas entre a produção, a experiência e o poder. Assim, a relação com o trabalho aparece como a combinação entre o social - expresso pela organização do trabalho, pela empresa de tipo 
capitalista e concorrencial, pela procura incessante de cada vez maior produtividade, por elementos culturais, simbólicos e históricos que envolvem a empresa e os cidadãos - e o individual - expresso através de como o homem vive seu trabalho.

\section{Autonomia no trabalho e mudança identitária}

Se a autonomia e a natureza coletiva do trabalho passam a ser intrínsecas à nova organização do trabalho, a nova ordem é "sejam sujeitos" e trabalhem em cooperação. Mas trata-se de uma cooperação produtiva e operacional e não, solidária e unificadora. A autonomia demandada ao trabalhador industrial implica o desdobramento das atividades desde o fazer até a compreensão do que é feito. A compreensão implica mobilização da inteligência, mas também do afetivo, que é justamente o surplus exigido. No entanto também o fazer implica uma dimensão de investimento pessoal na tentativa de fazer "bem", o que traduz um desejo de "fazer o belo", ${ }^{1}$ e constitui a zona de autonomia a mais pessoal, a mais completa e a menos suscetível de ser acionada por um comando externo à pessoa do trabalhador.

Trata-se não de simplesmente "fazer", mas de uma mudança no investimento identitário do trabalhador. Para atingir uma tal transformação, o management propõe que o trabalhador faça o trabalho como se fosse ele mesmo o empresário. Como? Através: 1) de uma "cultura da empresa" que, por meio, de uma caracterização da empresa e da disseminação de valores comuns ligados à dignidade e ao respeito aos trabalhadores, oculta a racionalidade da divisão do trabalho e da divisão econômica. A lógica do empresário deve passar a ser a lógica do operário; 2) de uma lógica unilateral em que a identificação à empresa se faz sem contrapartida contributiva

1 "Fazer o belo" - no original, faire le beau - remete ao trabalho feito com investimento pessoal e cujo autor é capaz de se identificar e se reconhecer no produto de seu trabalho. Ver DEJOURS, Christophe. Coopération et construction de l'identité en situation de travail. In: Futur Antérieur, n. 16, 1993/2. 
- sem aumento de salário - nem distributiva - sem ou com mínima participação econômica na receita da empresa e na distribuição da mais-valia; 3) da ameaça de não manter o operário em seu emprego, caso ele não se adapte às novas exigências. O preço da não adaptação à transformação é ser despedido ou bloqueado na sua evolução profissional; 4) da ausência de alguma forma de reconhecimento do trabalho operário: o trabalho em equipes autônomas dilui o julgamento dos pares (o trabalho em equipe limita-se ao "fazer" sem que se instaure uma real solidariedade) e o julgamento da hierarquia (a hierarquia oriunda do universo operário, o chefe que galgou postos até tornar-se chefe) é suprimida ou afastada em nome do trabalho autônomo. E ainda, os novos chefes diretos são jovens diplomados que não viveram a história operária e, por isso, deixam-nos expostos aos riscos da avaliação sem comprometimento pessoal.

A autonomia pode, assim, ser compreendida em dois sentidos: o primeiro, em seu sentido positivo, a autonomia real no trabalho que é a autonomia do "fazer bem", de "fazer o belo", que é reconhecido pelos seus pares. Essa autonomia permite proteger-se, uma vez que ela preserva o grupo como base identitária e possibilita um retorno sobre si mesmo, capaz de conferir um sentido ao trabalho. O segundo, em seu sentido instrumental, a autonomia é outorgada enquanto instrumento de coordenação das relações de trabalho e visa atingir um objetivo econômico de gestão da empresa. Essa autonomia aumenta a insegurança existencial do operário uma vez que ela enfraquece o investimento no "fazer o belo" em seu trabalho e reforça a destruição do grupo como base identitária. Essa autonomia propicia o aparecimento de estratégias individuais no seio do grupo de trabalho, as relações profissionais reforçam a relação à empresa e enfraquecem as relações entre os pares. Como? A autonomia outorgada enquanto instrumento do management visa mobilizar e integrar o trabaIhador ao processo de trabalho, de maneira a inserir nesse processo os elementos do trabalho que não podem ser prescritos, como a esperteza, a 
capacidade de coordenação, a concertação e a mobilização subjetiva. Mas o "dever-ser" autônomo já é uma injunção paradoxal, ${ }^{2}$ uma vez que se constitui em uma ordem a seguir que se traduz por uma mobilização pessoal. O "dever-ser" sujeito e autônomo assinala uma organização do trabaIho cada vez mais normalizada, ou seja, regida por normas.

A autonomia real é a iniciativa tomada, é a criação e o poder de decisão diante de uma situação imprevista. E estas situações existem sempre, mesmo que todos os esforços das organizações se orientem para uma previsão e uma prescrição máximas. Nas novas organizações, uma vez que uma iniciativa é tomada diante de um evento extraordinário, a hierarquia a integra imediatamente à regra, de maneira a difundir a intervenção e orientar todos os operadores. O extraordinário torna-se previsível, e a criação se enquadra na norma. A autonomia real torna-se heteronomia, uma vez que ela se transforma em uma ordem a seguir. Ao invés de uma autonomia real, trata-se agora de uma autonomia outorgada. Assim, a autonomia apresenta-se como um dom no qual o trabalhador é colocado mais uma vez como objeto e não como sujeito.

A garantia de qualidade passa pela normatização do trabalho, em que todos devem executar o trabalho da mesma maneira: uma maneira que deve integrar, com vistas à sua otimização, o savoir-faire operário. O processo de certificação ISO 9000 é exemplar da normatização da organização do trabalho: é preciso escrever o que se faz, é preciso fazer o que está escrito.

Exigir autonomia ao nível individual - e exercê-la - vai fragilizar os elos de aliança, de interdependência (mas não de interdependência funcional) e de mobilização coletiva da inteligência e da identificação. A autonomia outorgada é a transgressão autorizada e institucionalizada, de manei-

2 Trata-se de uma injunção paradoxal justamente por ser uma ordem impossível de ser obedecida, ou seja, a sua simples obediência acarreta a infração: a autonomia exigida significa a não obrigatoriedade de respeito às normas estabelecidas. Tal qual a ordem dada por uma mãe: "você tem o dever de me amar espontaneamente". Se ama espontaneamente, então não está cumprindo o seu dever. O mesmo se verifica caso não ame, o que acarreta uma situação sem saída. Cf. PALMADE, Jacqueline. Communication paradoxale et imaginaire consensuel. In: SFEZ, L. (sous dir.) Encyclopédie et Dictionnaire critique de la communication. Paris: PUF, 1993. 
ra que a aliança necessária para que os trabalhadores possam transgredir o prescrito em segurança é quebrada. Simultaneamente a autonomia outorgada mergulha os trabalhadores na ambivalência, uma vez que não é uma autonomia "real", ela é um instrumento de regulação entre criação e norma. A criação e o ato de liberdade são arrancados de seu autor para integrar a regra de execução das tarefas com vistas à sua otimização. De um lado, a autonomia é liberdade, de outro, ela é normatização.

A sobrevivência social torna-se profundamente dependente do desenvolvimento da empresa, há um enfraquecimento da relação simbólica ao trabalho e um reforço da relação à empresa, a identificação dos trabaIhadores não se dá mais ao trabalho mas à empresa. A solidariedade de classe dá lugar a solidariedades parciais precisas no tempo e no espaço. A organização, ao quebrar o coletivo de trabalho e ao instaurar a primazia do individualismo, induz uma solidariedade profissional, específica ao trabalho em equipe. $\mathrm{O}$ individualismo enfraquece o coletivo de trabalho, assim como a solidariedade profissional, pois ela também está inserida na lógica produtiva. O trabalho autônomo e a individualização imposta por uma organização do trabalho que exige cooperação, mas que não distribui nem poder nem compensação material, associada a um contexto de desemprego ou de precarização do emprego, induz a uma experiência compartilhada em detrimento de uma experiência coletiva. A experiência coletiva seria a base para a elaboração de um sentido comum, de uma compreensão comum da realidade. O reconhecimento do colega é o reconhecimento do outro, que também experimenta as dificuldades do mundo real - e do mundo do trabalho - e só este reconhecimento é capaz de fazer o trabalhador sair da sua solidão e se proteger da dominação através de estratégias coletivas de defesa. A questão, pois, que se coloca aqui é: como o operário vive a contradição entre um trabalho cooperativo que exige implicação subjetiva e a necessidade de uma inserção individual em uma organização que o mantém em situação de insegurança e que enfra- 
quece sua relação simbólica ao trabalho?

Na relação do operário ao trabalho, mundo objetivo e mundo subjetivo se confrontam. Esta confrontação faz com que o sujeito busque uma combinação "ótima", capaz de lhe garantir sobrevivência material e também psíquica. O trabalhador constrói uma inserção determinada na situação de trabalho, capaz de lhe proporcionar uma satisfação mínima e, ao mesmo tempo, experimenta os custos de suas escolhas. A estratégia individual é racional e irracionalmente determinada. O que permite afirmar que o sujeito termina por sofrer as conseqüências de sua estratégia individual de inserção na situação de trabalho. Assim, se o objetivo é investigar os efeitos da autonomia como norma sobre a relação ao trabalho, esta pode ser compreendida como sendo a associação entre a atitude ao trabalho, a estratégia individual e as determinações de ordem biográfica como pano de fundo.

O estudo da relação ao trabalho culmina com uma proposição de tipologia. Essa tipologia baseia-se naquilo que é verdade para os entrevistados, naquilo que eles exprimem e sentem como sua realidade no trabaIho. Há uma reconstrução pessoal da vida, no trabalho de cada operário entrevistado, e suas razões individuais alimentam a constituição de um tipo ideal. A realidade concreta e observável do trabalho não foi desconsiderada, ela se faz necessária para dar sentido e significação às palavras que exprimem a realidade para a pessoa ao trabalho. Mas a tipologia se constrói sobre a verdade para o sujeito, e o dado empírico e objetivo tem tão somente valor heurístico.

A pesquisa comparativa França-Brasil (1993-95): uma proposta de tipologia

A tipologia expõe a maneira pela qual os trabalhadores da indústria química reagem à demanda de autonomia por parte da organização, levan- 
do em conta, para isso, suas trajetórias profissionais individuais, suas vivências anteriores, suas perspectivas e expectativas quanto ao futuro, suas percepções a respeito de suas capacidades e, mais especificamente, sua capacidade de adaptação às novas exigências, suas relações com a empresa enquanto organização, suas atitudes de resistência ou de conformidade às exigências de autonomia e iniciativa no trabalho, de identificação à lógica econômica e, finalmente, como associam um trabalho de equipe a uma estratégia individual de inserção na organização. A relação com o trabalho se insere em quatro modelos: a adesão formal, a adesão ambivalente, a recusa e $o$ recuo. ${ }^{3}$ A adesão formal é característica dos trabalhadores que se identificam de maneira categórica com o trabalho e com o projeto da empresa, sem elaborar críticas ou recuos importantes, o que, finalmente, favorece uma adesão concreta e o engajamento ao trabalho. A adesão ambivalente é o resultado da associação entre o desejo de se integrar à nova organização do trabalho e o desejo de resistir a essa integração, entre o princípio de realidade (é absolutamente necessário adaptar-se) e o desejo que remete ao eu-verdadeiro (ligado aos valores que remetem à justiça, à liberdade e a outras lógicas que não somente a lógica econômica). A recusa é marcada pela rejeição à lógica dominante. Estes trabalhadores encontram-se na negatividade e sem esperança de ter realmente a escolha de deixar este emprego. O recuo aparece somente na França e atinge os operários de mais idade que vivem uma certa nostalgia dos velhos tempos, quando a classe operária era unida e combativa. As relações com a hierarquia eram, certo, marcadas pela autoridade do chefe, mas eram, no entanto, mais claras e mais simples. A adesão formal é mais importante no Brasil, o recuo só existe na França e diz respeito a um número também importante de entrevistados franceses.

A adesão formal é uma adesão mais "fusional" ao trabalho e ao projeto da empresa. Por que formal? Porque é mais uma crença que uma vivência. A mudança organizacional é um imperativo a seguir, e o trabalha-

3 Aderir, como a palavra evoca, significa colar-se, associar-se, dar um assentimento e se declarar de acordo. Aderir ao trabalho remete à idéia de que o trabalho deve ser tomado tal qual ele é proposto: se adere àquilo que já está pronto. 
dor o segue corretamente e com um enorme desejo de êxito. Os juízos pessoais estão ausentes do seu discurso ou são negados. Se o operário vislumbra, através de sua adaptação, perspectivas de ascensão profissional ou de estabilidade em uma trajetória exitosa até ali, ele aceita e adere ao que lhe é proposto. A adesão formal apresenta um discurso de mesma natureza que a récita - é preciso repetir a lição aprendida, sem se perguntar demais -, e uma natureza de incondicionalidade, visto que é uma maneira - constrangida ou espontânea - de negar qualquer ambivalência. Essa negação é um indicativo, justamente, do caráter ambivalente da adesão formal. Ela permite defender-se da dualidade e de salvaguardar sua natureza incondicional ou peremptória de adesão. A autonomia outorgada induz a uma adesão ambivalente que, ao nível da ação, exprime-se por uma adesão formal ou pela própria adesão ambivalente. No interior do grupo caracterizado pela adesão formal ao trabalho, é possível fazer aparecer três subgrupos ${ }^{4}$ : o primeiro - aquele que define o grupo - é formado pelos trabalhadores brasileiros que vislumbram um ganho com a nova organização, têm uma identificação idealizante à empresa e aderem ao trabalho proposto de maneira incondicional e universal. O segundo é formado pelos trabalhadores franceses que também vislumbram um ganho e têm uma inserção estratégica, como seus homólogos brasileiros, mas mantêm um silêncio estratégico em relação a esses ganhos, visto que eles trabalham lado-a-lado com trabalhadores que são perdedores. Sua adesão é constrangida e necessária. O terceiro é igualmente formado por trabalhadores franceses e brasileiros, e eles aderem ao trabalho visando a continuidade. Eles se adaptam, eles agem em conformidade às regras, eles têm uma adesão também necessária e constrangida, para não perder aquilo que já foi conquistado e poder prosseguir numa trajetória já em parte transcorrida.

A adesão ambivalente introduz a dúvida e a hesitação no discurso

4 Sendo a realidade muito mais dinâmica e complexa que a tipologia, é possível observar a existência de subgrupos no interior destes modelos. Eles indicam algumas tendências no seio de cada grupo ou modelo, mais do que verdadeiramente subgrupos com características claras e distintas. 
sobre o trabalho. Há também adesão e uma certa satisfação com o trabalho presente ou projetado, assim como o relato de ganhos presentes ou futuros, mas o trabalhador se interroga e hesita. Ele adere, mas experimenta o gosto da insegurança e da injustiça, ele adere, mas com um certo recuo e desconfiança. A adesão ambivalente caracteriza a relação ao trabalho daqueles que permitem aceder à consciência os elementos negativos que se escondem atrás da ambivalência, mas que, de qualquer maneira, mantêm a adesão ao trabalho e ao projeto da empresa. De um lado, há um investimento real diante de possibilidades de carreira reais ou esperadas ou ainda de possibilidades de continuidade; de outro, há uma resistência consciente e/ou inconsciente para com uma organização que retira do trabalhador uma real autonomia e todas as formas de reconhecimento do seu trabalho. Tal resistência torna-se evidente quando, por exemplo, ter perspectivas concretas de evolução de carreira provoca no sujeito um processo de culpabilização. Mas ter um trabalho e se engajar a fim de progredir não é somente desejável, mas também inevitável. A ambivalência é, assim, a associação entre o desejo de integração e a defesa em relação a essa integração, entre o investimento pessoal e o recuo. No seio do grupo marcado pela adesão ambivalente é possível perceber três subgrupos. Primeiramente o subgrupo presente na França e no Brasil e que define o modelo: eles desejam investir-se no trabalho - porque se sentem capazes e crêem no valor do trabalho - mas eles têm consciência da contradição intransponível entre capital e trabalho, cujas conseqüências são a impossibilidade de concretizar o valor do trabalho tanto a partir da transparência das relações entre os trabalhadores e a hierarquia quanto a partir do reconhecimento real do trabalho operário. Eles continuam profundamente ligados ao seu trabalho, fazendo o melhor possível e permanecendo atentos aos outros, mas manifestam sua atenção aos aspectos destrutivos das mudanças ao nível material e identitário. Eles criticam e se investem.

O outro subgrupo do modelo de adesão ambivalente só existe no Brasil e diz respeito àqueles que, diante de sua incapacidade ou resistência 
de adaptar-se às novas exigências, são levados a negar essa incapacidade com um sentido de preservação. Eles se sentem fragilizados pela sua impossibilidade de acompanhar as mudanças e experimentam a necessidade de anular a ameaça de desemprego ou bloqueio em sua evolução que essa incapacidade implica.

O subgrupo francês do modelo de adesão ambivalente é simbolicamente revelador dos valores presentes entre os trabalhadores franceses: sua ambivalência nasce do sentimento de culpa de ter a ganhar com essa nova maneira de trabalhar. Eles possuem possibilidades reais de progressão profissional ou uma trajetória operária já exitosa, mas se sentem culpados desse sucesso no interior de uma organização que fragiliza e obriga uma identificação à racionalidade econômica, quando eles estão embebidos de valores de solidariedade e de justiça social.

Os modelos de recusa e de recuo não apresentam subgrupos. A recusa é a mesma na França e no Brasil, é fruto da tomada de consciência dos aspectos negativos apresentados pela nova organização. Se não há qualquer benefício, o trabalhador recusa de maneira crítica aquilo que lhe é proposto. O trabalho pode sempre ser feito de maneira correta, mas um posicionamento de negatividade resulta em um desinvestimento no trabaIho. Trata-se de um posicionamento de resistência e de oposição que conduz a uma relação instrumental com o trabalho, uma vez que, ao lado da recusa e da perda de toda expectativa, há a necessidade de prosseguir, de manter o emprego, de se adaptar minimamente. O recuo é característico dos trabalhadores franceses que se "retiram" simbolicamente do mundo do trabalho, após muitos anos de vida operária e após haver conhecido as lutas e conquistas operárias. Eles se retiram e vivenciam a perspectiva mais ou menos próxima da aposentadoria. O recuo, ao contrário da recusa, repousa sobre uma identificação simbólica parcial à empresa, já que esses operários vivenciaram anteriormente uma situação de investimento ao trabalho, alimentada por uma implicação política e social. Seu sentimento é de perda. 


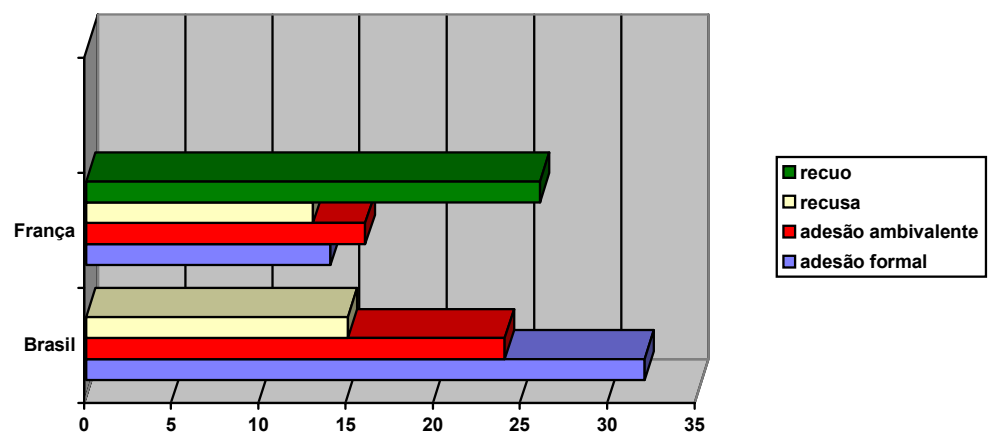

Gráfico 1. A relação ao trabalho por país Fonte: Pesquisa empírica

A tipologia torna comuns os aspectos da relação ao trabalho diretamente ligados à organização do trabalho que outorga a autonomia e cujas exigências se inserem no quadro do capitalismo mundial. Mas torna evidente também as diferenças entre os dois países naquilo em que a história e a constituição socioeconômica de cada um contribui para a construção da relação ao trabalho.A tipologia torna comuns os aspectos da relação ao trabalho diretamente ligados à organização do trabalho que outorga a autonomia e cujas exigências se inserem no quadro do capitalismo mundial. Mas torna evidente também as diferenças entre os dois países naquilo em que a história e a constituição socioeconômica de cada um contribui para a construção da relação ao trabalho.

No momento em que se comparam as diferenças e similitudes entre os dois países, a questão das determinações macrossociais dessas diferenças e semelhanças se coloca. Como explicá-las? Se, de um lado, a vivência do trabalho é ela própria uma fonte de compreensão, de outro, os elementos de ordem social podem contribuir como variáveis para a constru- 
ção de uma atitude no trabalho. Existe uma determinação mútua destes processos culturais e sociais, e, à luz dessa interdependência, procurou-se responder às seguintes questões: por que os trabalhadores brasileiros aceitam mais e melhor as novas exigências impostas pela organização? Por que eles são mais "fusionais" em sua relação com o trabalho? Por que, ao contrário, os trabalhadores franceses oferecem mais resistência e assumem uma posição de recuo? Por que uma relação com o trabalho marcada pela ambivalência cria um subgrupo marcado pela culpa, na França, e um outro mais fragilizado, no Brasil? Por que o trabalhador brasileiro com relação de adesão formal ao trabalho proclama e propaga sua satisfação e sua identificação com o projeto da empresa, enquanto o francês opta por se calar? Qual é o papel da história do movimento operário na França na constituição de um grupo de "resistentes nostálgicos", inexistentes no Brasil?

A tipologia evidencia os aspectos comuns da relação com o trabalho diretamente ligados à organização do trabalho que outorga autonomia e cujas exigências se inserem no quadro do capitalismo mundial. Mostra também as diferenças entre os dois países e as evidências daquilo que a história e a constituição socioeconômica de cada um contribui para a construção da relação com o trabalho. O Brasil é um país marcado por um passado de trabalho escravo, por desigualdades econômicas e sociais, pelos desequilíbrios regionais, pela concentração de terras nas mãos de uns poucos, por uma urbanização descontrolada, pela educação e pela saúde inacessíveis à maioria da população, pelos sindicatos estruturados sob a tutela do Estado, por uma proteção social aos trabalhadores nem sempre respeitada. No entanto, o País dispõe de um parque industrial importante e diversificado, apresenta uma melhora nos indicadores de desenvolvimento, fez sem maiores dificuldades a reestruturação produtiva imposta pela abertura e globalização dos mercados. A França vivenciou o crescimento econômico, o Estado protetor, o Direito republicano, os sindicatos 
livres para se confrontarem, mais recentemente experimentou um processo de desindustrialização (as empresas transnacionais se espalham pelo mundo), de globalização dos mercados, de enfraquecimento do welfare state, de redução do P.I.B. e de desemprego estrutural. Os dois países integram um mesmo movimento do capitalismo mundial, mas se inserem com uma história econômica e social diferente. Se o que predomina entre os operários franceses é um sentimento de perda, compreende-se melhor que uma parte daqueles que apresentam uma adesão formal ao trabalho experimenta culpa e vergonha. Igualmente, uma parte daqueles que manifestam uma adesão formal ao trabalho se calam, já que dificilmente podese fazer a récita dos ganhos em um contexto no qual o que predomina é, em maior ou menor medida, um sentimento de perda. Quanto aos brasileiros que conhecem um contexto de pobreza, de fraca escolaridade, de alta mortalidade infantil, um seguro desemprego insuficiente, trabalhar sob um contrato formal em uma empresa multinacional e contar, ao mesmo tempo, com organizações de trabalho mais liberais e mais participativas, só pode representar um benefício. Isso não significa que não haja perda no Brasil: ao contrário, aqueles que estão fragilizados e vêem seu emprego em risco são a própria concretização da perda, mas uma perda que não é anulação de antigas conquistas e uma segurança já vivida, mas bem mais uma perda real de um emprego assalariado e formal. O passo seguinte é a exclusão ou a precarização.

\section{A pesquisa no Pólo Petroquímico de Triunfo (2000-1)}

A pesquisa realizada em uma empresa petroquímica do Pólo Petroquímico de Triunfo (RS) seguiu a mesma metodologia utilizada na pesquisa que a antecedeu e visava utilizar a tipologia então proposta como instrumento de compreensão da realidade, no que diz respeito aos trabaIhadores brasileiros. Em uma empresa altamente automatizada e 
informatizada - comparativamente mais moderna que aquela pesquisada na outra ocasião, tanto na França quanto no Brasil - foram feitas entrevistas em duas unidades distintas. A empresa estava em pleno processo de expansão econômica e havia recentemente aumentado suas instalações e implementado novas unidades de produção. Com um investimento tecnológico importante, com uma produção de alto risco (produtos e processos potencialmente perigosos), e com trabalhadores em número reduzido e com muita qualificação, todo trabalho fora da sala de controle e do controle direto das instalações era terceirizado. Os entrevistados possuíam o perfil típico do "novo operário", esta elite operária que tem "a ganhar" com este tipo de seleção no interior da classe operária.

A autonomia outorgada e a normalização do saber prático operário se materializa com nitidez, nesta empresa, através dos Círculos de Controle de Qualidade (CCQ) - instrumento organizacional importante na empresa pesquisada - cujo objetivo é aumentar a produtividade e a qualidade, economizar tempo, material e energia, aumentar a segurança do trabalho, preservar o meio ambiente e promover a cooperação mútua. Tais objetivos devem ser atingidos através de grupos de trabalho que elaboram projetos de melhorias. Se a melhoria é implementada, o grupo é premiado. Alguns entrevistados apontam uma transferência de responsabilidades através dos CCQs, uma vez que também o trabalho de pesquisa e aperfeiçoamento é executado pelos trabalhadores, além de todo o trabalho cotidiano de condução das instalações.

Eu acho que traz resultados, mas eu acho que é um programa que precisa ser revisto porque, é como eu te comentei, a gente está com um volume de trabalho muito grande, muito serviço, cada vez implementa-se mais rotinas e a gente tem que contemplar essas rotina, aí o CCQ entra junto nisso aí. Então tu tem que fazer todo o teu serviço, é comum às vezes faltar pes- 
Sociologias, Porto Alegre, ano 5, no 10, jul/dez 2003, p. 350-378

soal na área pra nós aqui, então tu já fica com mais serviço ainda, porque tu acumula função de outra área, e ainda no meio tempo tu tem que fazer $5 S-C C Q$, né? Tem ocorrido isso aí. Até na zero hora agora, zero hora tu sabe, a gente trabalha em turno, né? Em escala. Na zero hora é um período que a gente consegue fazer mais CCQ, mas dificulta na medida que tu tem que elaborar o projeto, tem essa parte de engenharia do projeto, aí tem que fazer o descritivo do projeto, tu tem que pegar um telefone para entrar em contato com uma empresa para fazer um orçamento de quanto vai sair o projeto, fazer o custo do projeto inteiro. Então nesse ponto acho que dificulta porque a gente está acumulando função que eu acho que não deveria ser nossa. Do CCQ eu teria a dizer isso, acho que não deveria ser uma coisa, uma coisa tão centrada no operador, fazer tudo. Eu sei que de repente a engenharia está sobrecarregada também, mas tem coisas que fica ruim. A gente só trabalha em ADM (horário administrativo, das 8 às $17 \mathrm{hs}$ ) sete dias em trinta e cinco, tá? Então não tem condição de fazer pesquisa de preço de tubulação ou de não sei o que durante a zero hora. Então eu tenho sete dias em trinta e cinco para fazer pesquisa de mercado, para ver se vai ser viável meu projeto ou não. Isso aí acaba tornando lento o processo. Eu acho que isso aí é um ponto que poderia ser melhorado, na minha ótica (operador trainee).

Todo o processo é de responsabilidade do grupo: desde a concepção até a sua viabilidade técnica e financeira. O que, sem dúvida, significa acúmulo de trabalho. Não há, de fato, a possibilidade de não participar dos CCQs: aquele que não participa é aquele que não se envolve com as melhorias e, logo, não se investe no trabalho. 
Outro trabalhador acrescenta que o retorno para os trabalhadores das melhorias concebidas e aplicadas não é prioritariamente financeiro: o prêmio não é proporcional ao ganho da empresa, os ganhos para os trabalhadores são, sobretudo, em termos de segurança e racionalização do trabalho. Assim, o ganho financeiro é da empresa e o retorno em termos de criatividade, segurança e facilitação do trabalho é dos trabalhadores.

O projeto CCQ é bom, né? É bom para a empresa, mais para a empresa, porque existem muitos projetos $C C Q$, a maior parte, vamos dizer, não dá o retorno. $A$ maior parte não dá o retorno direto, embora já tenha recebido por um projeto. Mas a maior parte não te dá retorno financeiro. Se dá retorno financeiro, dá para a empresa. E em última análise, se a empresa está bem, tu está bem também. (...) É assim, porque existe os que dão retorno financeiro e os que dão, por exemplo, o retorno em segurança, o retorno na facilidade de operar, se tornam mais fáceis de operar, ou se tornam mais seguros de operar. Então têm os que dão retorno financeiro são o que o grupo fez o projeto, depois de ter sido feito e ter sido implantado, acho que um ano depois ele é avaliado e é medido o que ele trouxe de retorno financeiro para a empresa, né? Aí, no caso, os participantes daquele grupo recebem um prêmio que não tem nada a ver com o retorno, não é em função do retorno financeiro (operador de processo II).

Os trabalhadores são impelidos a participar, cada vez mais, na concepção da maneira "ótima" de se realizar o trabalho. Seu saber prático e a esperteza de seu savoir-faire são integrados à organização do trabalho, de maneira a inseri-los na norma. Os modelos de adesão ao trabalho e ao projeto organizacional proposto pela empresa supõem a obediência a es- 
sas novas exigências.

Os entrevistados, em sua maioria, surpreendiam pelo seu alto grau de conformismo onde não havia espaço - ou o espaço era reduzido - para apresentar manifestações de resistência, de crítica ou de descontentamento em relação ao trabalho e à empresa. Quando a crítica se fazia presente, estava associada ao conformismo ou à satisfação em integrar aquela organização, postura típica da adesão ambivalente. É certo que eles dispõem de boas condições de trabalho e ainda dispõem de autonomia no trabaIho, mas há algo sobre o que refletir quando a satisfação não permite hesitações e não oferece nenhuma resistência a um trabalho que, sem dúvida, é exercido sob uma grande pressão: pressão para não cometer erros (as conseqüências podendo ser a explosão das instalações e a morte), pressão para se superar constantemente, pressão para se integrar e trabalhar em equipe (durante os dias de folga, já que o trabalho é feito em revezamento de equipes, a empresa "oferece" - não há a opção real de não participar jogos em parques que se assemelham a exercícios militares a fim de promover o trabalho em equipe, o autocontrole e a supervisão do grupo), pressão para não perder um trabalho considerado vantajoso no contexto atual do mercado de trabalho (a estabilidade de uma empresa em crescimento, assistência médico-hospitalar privada, transporte gratuito, salários, no mínimo, na média do mercado). Parece que a adesão formal, e a adesão ambivalente de maneira secundária constatada alguns anos antes, tomou uma forma e uma generalidade importantes. Ou os entrevistados decidiram nada dizer a esse "terceiro" - o pesquisador - que se apresenta a eles e que pode ser visto como um fator de desequilíbrio em uma situação que se encontra sob controle, mas o que, de toda maneira, já é em si mesmo um dado importante a considerar, ou os trabalhadores entrevistados não se permitem ver a realidade com outros olhos que não aqueles desejados pela organização. O modelo de recusa não existe entre os trabaIhadores entrevistados. Como se o mundo do trabalho houvesse tido êxito 
em reduzir a identidade das pessoas no trabalho - ao menos neste tipo de indústria e submetidas a uma tal organização do trabalho - a uma identidade exclusivamente operária, a uma identidade exclusiva ao trabalho. A adesão formal do tipo incondicional e adesão ambivalente - dividida entre o investimento e a crítica ao trabalho - foram os modelos encontrados entre os trabalhadores entrevistados no Pólo Petroquímico.

Eugène Enriquez (2000) discute claramente a questão da conformidade às novas exigências, quando afirma que os indivíduos abdicam de ver as coisas de outra maneira, de serem críticos, de viverem uma vontade de não-assimilação total. Como afirma o autor: "com efeito, a armadilha por excelência reside nas transformações de mestres (ou chefes) em estrategistas sedutores declarando aos dominados que eles podem fazer parte, um dia, da sua confraria" (ENRIQUEZ, 2000, p. 47). ${ }^{5}$ O discurso da empresa é atraente e sedutor para o trabalhador (você vai crescer na empresa, obter um lugar de acordo com suas competências), mostrando que um dia eles poderão fazer parte desta confraria tal qual sua hierarquia. Esta, por sua vez, perde a posição de comando para assumir a de animador, conseIheiro, que consulta e faz participar (autonomia outorgada). As resistências tendem a se anular, mas eles pagam o preço através do stress e das doenças psicossomáticas.

É grande a apatia dos indivíduos em contraposição ao poderio das grandes organizações, o que favoreceria, segundo Enriquez, a adesão e a "obediência irrefletida". Parece-nos também uma obediência refletida, dadas as condições sociais do emprego nos nossos dias. Mas parece indubitável, como na lei da física, que a fim de diminuir a força "contra" exercida em reação a uma força autoritária, trata-se agora de não exercer força nenhuma e assim não encontrar resistência. A sociedade não tem mais motivos para multiplicar as regras coercitivas e imperiosas para se fazer obedecer e obter a conformidade. "Os indivíduos interiorizaram suficientemente a mensagem para não precisar se dobrar a um 'agressor' 
exterior" (ENRIQUEZ, 2000, p. 46).

O quadro que segue sistematiza a relação com o trabalho e a tipologia apresentada:

Quadro 1.

\begin{tabular}{|c|c|c|}
\hline FRANÇA (1993-4) & BRASIL (1994-5) & $\begin{array}{l}\text { PÓLO PEIROQUÍMICO } \\
\text { (2001) }\end{array}$ \\
\hline Relação com o trabalho & Relação com o trabalho & Relação com o trabalho \\
\hline $\begin{array}{l}\text { Adesão formal } \\
\text { (1) Ganho } \rightarrow \text { adesão } \\
\text { constrangida } \\
\text { (2) Adaptação/conformismo } \rightarrow \\
\text { adesão constrangida }\end{array}$ & $\begin{array}{l}\text { Adesão formal } \\
\text { (1) Ganho } \rightarrow \text { adesão } \\
\text { incondicional } \\
\text { (2) Adaptação/conformismo } \rightarrow \\
\text { adesão constrangida }\end{array}$ & $\begin{array}{l}\text { Adesão formal } \\
\text { (1) Ganho } \rightarrow \text { adesão } \\
\text { incondicional } \\
\text { (2) Adaptação/conformismo } \\
\rightarrow \text { adesão constrangida }\end{array}$ \\
\hline $\begin{array}{l}\text { Adesão ambivalente } \\
\text { (1) Crítica/investimento } \\
\text { (2) Ganho/culpa ou vergonha }\end{array}$ & $\begin{array}{l}\text { Adesão ambivalente } \\
\text { (1) Crítica/investimento } \\
\text { (2) Incapacidade ou } \\
\text { resistência à adaptação/sua } \\
\text { negação }\end{array}$ & $\begin{array}{l}\text { Adesão ambivalente } \\
\text { (1) Crítica/investimento }\end{array}$ \\
\hline $\begin{array}{c}\text { Recusa } \\
\text { Negatividade }\end{array}$ & $\begin{array}{c}\text { Recusa } \\
\text { Negatividade }\end{array}$ & \\
\hline $\begin{array}{l}\text { Recuo } \\
\text { Nostalgia }\end{array}$ & & \\
\hline 69 & 71 & 40 \\
\hline
\end{tabular}

Liberdade, resistência e autonomia outorgada

A armadilha da autonomia outorgada remete à própria ambigüidade de sua formulação: ser simultaneamente uma injunção a participar e o objeto de uma ordem a ser seguida. Esta exigência de uma mobilização subjetiva por parte da empresa impulsiona os trabalhadores a um impasse. Para continuar a trabalhar, para manter uma posição já adquirida, para responder a exigências de investimento pessoal sem garantia de retorno identitário - uma vez que a autonomia é uma pseudo-liberdade - torna-se imperativo adaptar-se continuamente e relegar a segundo plano o olhar crítico ou desviante. Para adaptar-se, os trabalhadores buscam recompensas 
materiais e/ou simbólicas que podem reduzir-se a conservar seu posto de trabalho e à inserção social atual. Tudo aceitar não significa conformar-se a tudo, mas encontrar uma orientação para a ação, capaz de garantir um mínimo de continuidade. O indivíduo reduz o self ao mínimo, de maneira a ser capaz de manter uma existência simbólica e material: simbólica ao preservar uma margem mínima de liberdade e autonomia individual, material ao preservar o emprego - o que remete igualmente ao simbólico, na medida em que o trabalho continua a ser o "suporte privilegiado de inscrição na estrutura social" (Castel, 1995).

Esta orientação para a ação torna-se um mecanismo de sobrevivência e obriga a desenvolver estratégias individuais de inserção. A individualização é uma resposta à batalha identitária (Linhart, 1998) em que se lançam as organizações ao demandarem a mobilização subjetiva dos trabalhadores: assiste-se a uma luta individual para se inserir - e talvez se integrar - e simultaneamente a uma luta individual visando salvaguardar os valores e a coerência pessoal. Essa luta individual favorece o enfraquecimento das antigas solidariedades de métier para fortalecer a identificação aos valores da empresa. Em um contexto de desemprego crescente, o empobrecimento do reconhecimento dos pares pelo enriquecimento das estratégias individuais de inserção e de um processo de individualização e de isolamento incita à competição entre trabalhadores. A luta de classes dá lugar à luta de colocações e classificações. A vivência no trabalho e os elementos sociais se associam para aumentar o isolamento e a solitude; o individualismo é "negativo" (Castel, 1995) uma vez que ele se traduz em termos de 'falta': falta de consideração, de segurança, de bens assegurados, de elos estáveis, de reconhecimento, de controle do futuro, de respeito aos valores essenciais, de intervenção no devir da sociedade, do poder das ações coletivas. A vida no trabalho encontra-se marcada pela perda: perda daquilo que o trabalho era ou devia ser. Se não se pode falar do fim do valor trabalho - já que apesar da perda de sua capacidade de conferir 
um sentido à vida social, o trabalho continua a servir de mediação e laço social - pode-se ao menos constatar o enfraquecimento simbólico da relação com o trabalho entre os operários industriais. O presente é mais importante que o futuro, trabalhar significa adaptar-se a qualquer exigência, e ser ator de si mesmo perdeu a força diante do domínio da racionalidade econômica.

Ao se analisar a questão da autonomia no trabalho, encontra-se a idéia de que a organização outorga uma "liberdade" - dentro da situação de trabalho - que remeteria a uma liberdade de si, já que a mobilização subjetiva exigida pela organização do trabalho permitiria a realização pessoal - de si - no trabalho. Partindo da hipótese de que a coerção, de maneira geral, significa retirar do homem sua liberdade, ou uma parte dela, pode-se perguntar sobre a idéia mesma de liberdade. Isaiah Berlin analisa a liberdade em duas de suas múltiplas versões: a liberdade negativa e a liberdade positiva (BERLIN, 1979). A liberdade negativa se define pela não-interferência dos outros homens sobre a ação ou sobre o ser e se opõe à idéia de coerção. A liberdade positiva remete ao desejo do homem de ser mestre de si mesmo, ou seja, à sua aspiração a ser sujeito e não objeto.

De nossa parte, apoiando-se sobre esses conceitos, de natureza mais geral e política, a fim de fazer um paralelo com a imposição de autonomia, é possível levantar a hipótese de que a ausência de liberdade negativa se dá ao nível da autonomia outorgada - a coerção de ser autônomo -, mas em nome da liberdade positiva - tornar-se sujeito do trabalho. Dito de outra maneira, em nome da liberdade positiva justifica-se a coerção. Esta, em oposição à liberdade negativa, implica a interferência deliberada do outro em um domínio no qual a pessoa poderia fazer diferentemente daquilo que é estabelecido. Ao nível social, pode-se pensar que a ausência de toda coerção pode significar o caos e que a liberdade do homem deve ser limitada pela lei (Locke et Tocqueville) ou pela moral enquanto consciência coletiva (Durkheim). A liberdade positiva, por sua vez, pode servir 
para justificar a coerção ao apelar aos valores e ao legitimar a ação através de objetivos e de proposição de valores socialmente reconhecidos como, por exemplo, a justiça. Nesse sentido, torna-se possível conceber a coerção sobre o outro em nome do seu próprio interesse, o que significa que aquele que se impõe sabe mais sobre o outro que ele mesmo. Assim, a coerção não é mais coerção uma vez que ela outorga um bem àquele que não conhece o que é um bem para si mesmo.

A outorga de autonomia no trabalho aparece, finalmente, como uma pseudo-liberdade: em nome de um vir a ser sujeito, o trabalhador é remetido, uma vez mais, à sua condição histórica de objeto, e, em nome de uma maior liberdade, legitima-se um imperativo de mobilização subjetiva e de implicação pessoal.

Se compararmos os modelos de relação com o trabalho na tipologia proposta em nossa primeira pesquisa com aqueles encontrados na segunda, é possível afirmar que o modelo de adesão formal é aquele que predominava entre os trabalhadores brasileiros nos primeiros anos da década de 90, e aquele que se mantém como predominante entre os trabalhadores no início da década seguinte, quando inseridos em grandes empresas de processo com alto investimento tecnológico. A sua condição de "privilegiados" no contexto do mercado de trabalho remete a uma posição protetora de conformidade. Ao adotar o ponto de vista da empresa, o trabalhador se protege dos riscos de um posicionamento de resistência. A interiorização das normas e do ponto de vista do dominante garantem um modo de existência previsível e, portanto, seguro. Eles se identificam com a empresa e suas mudanças de maneira idealizante: o lado opressor da sua lógica produtivista é anulado ou negado (a empresa que demite, que fragiliza pela dependência aqueles que ficam, que impõe a supremacia da lógica econômica sobre todas as outras), enquanto o lado "bom" da empresa é enaltecido (ela assegura - no caso de se conformar às regras - trabalho, emprego, promoções, salário, desenvolvimento econômico, recompensas). 
Identificando-se à empresa como se ela fosse somente "boa", a identificação torna-se parcial e idealizante: a adesão é formal porque, embora presente, ela não é completa. A identificação idealizante contribui para uma adesão concreta, consolidada pelos benefícios pessoais e materiais.

Os poucos que arriscam uma posição mais crítica, um olhar destoante sobre a realidade, fazem-no guardando o desejo de integração à empresa, de segurança e permanência, o que caracterizaria uma adesão ambivalente. Num mundo do trabalho dominado pela racionalidade econômica, mas que deseja igualmente mobilizar no interior da sua própria lógica a racionalidade subjetiva, a ambivalência significa não ter havido êxito em afastar os elementos que remetem aos valores, o que se traduz por uma relação conflituosa entre o desejo de integração a esse mundo e o medo e/ou a recusa de se integrar a ele. A ambivalência aparece em função de um desejo de integração e uma resistência a essa integração: integrar-se porque é uma necessidade existencial e pode significar ganhos materiais; resistir porque há dúvidas quanto à legitimidade social dos fundamentos dessa organização e daí o desejo de não fazer parte dela. É importante notar que este modelo caracteriza a irrupção da crítica, do olhar diferente daquele que é dominante, do desejo de não-assimilação. Mas sempre confrontado ao desejo e à necessidade de integração, de tornar-se membro da organização. A resistência se enfraquece, e aderir às novas exigências é imperativo. O modelo de recusa outrora identificado, sequer aparece na nova conjuntura. Como se aumentasse a sedução e diminuísse a resistência.

Se o prazer e a realização de si se encontram justamente no espaço criador que preenche o hiato entre a regra e a ação e que é o espaço da autonomia real onde o indivíduo se reconhece como sujeito e não como objeto da regra, a autonomia outorgada engaja os trabalhadores a trazerem sua contribuição pessoal, mas mantendo sua natureza de ordem a ser obedecida e despojando-os de uma autonomia e liberdade reais. Obedecer significa adaptar-se às novas exigências formuladas pela nova organização do trabalho. 
Esta é capaz de enriquecer o conteúdo do trabalho, torná-lo mais variado e mais interessante, de aumentar a satisfação no trabalho, mas é incapaz de permitir mais que uma adesão formal e/ou ambivalente ao trabalho.

\section{Referências}

BERLIN, Isaiah. Four essays of liberty. Oxford: Oxford University Press, 1979 [1969].

BERTRAND, Michèle. L'homme clivé, la croyance et l'imaginaire. In: BERTRAND, M. et all. Je, sur l'individualité. Paris: Messidor/ Éditions Sociales, 1987, p. 17-48.

BORZEIX, Anni. La parole en sociologie du travail. In: BOUTET, Josiane (sous la direction). Paroles au travail. Paris: L'Harmattan, 1995.

CASTELS, Manuel. La société en reseaux. Paris: Fayard, 1998.

DEJOURS, Christophe. Analyse psychodynamique des situations de travail et sociologie du langage. In : BOUTET, Josiane (sous la direction). Paroles au travail. Paris: L'Harmattan, 1995, p. 181-224.

DEJOURS, Christophe. Coopération: et construction de l'identité en situation de travail. In: Futur Antérieur, Paris, no16, 1993/2.

DUBAR, Claude. La socialisation; construction des identités sociales et professionnelles. Paris: Armand Colin, 2o ed., 1996 [1991].

ENRIQUEZ, Eugène. Une société sans résistance. In: Revue L'Inactuel, Paris, Circé, no4, printemps, 2000.

GORZ, André. Misères du présent, Richesse du possible. Paris: Galilée, 1997.

LAZZARATO, Maurizio. Le concept de travail immatériel: la grande entreprise. In: Futur Antérieur, n 10, Paris, L’Harmattan, 1992/2.

LINHART, Danièle. A propos du post-taylorisme. In: Sociologie du travail, Paris, XXXV, no1, 1993. 
Sociologias, Porto Alegre, ano 5, no 10, jul/dez 2003, p. 350-378

LINHART, D. \& LINHART, R. L'évolution de l'organisation du travail. In : KERGOAT, J. et al. Le monde du travail. Paris: La Découverte, 1998.

PALMADE, Jacqueline. Communication paradoxale et imaginaire consensuel. In : SFEZ, L. (sous dir.) Encyclopédie et Dictionnaire critique de la communication. Paris: PUF, 1993.

PERRET, Bernard. L'avenir du travail. In: BOISARD, Pierre et al. Le travail, quel avenir? Paris: Gallimard, 1997, p. 1-33.

SAINSAULIEU, Renaud (sous direc.). L'entreprise, une affaire de société. Paris: Presses de la Fondation Nationale des Sciences Politiques, 2oed., 1992 [1990].

\section{Resumo}

Este estudo analisa os efeitos do processo de reestruturação produtiva sobre a relação com o trabalho, entre os trabalhadores industriais do setor químico. Tal objeto direcionou duas pesquisas empíricas: a primeira em uma mesma empresa na França e no Brasil, a segunda no Pólo Petroquímico de Triunfo. Tem como eixo o conceito de autonomia no trabalho, que pode ser compreendido em dois sentidos: em seu sentido positivo, a autonomia real no trabalho que é reconhecido pelos pares e permite proteger-se, uma vez que ela preserva o grupo como base identitária e possibilita um retorno sobre si capaz de conferir um sentido ao trabaIho. Em seu sentido instrumental, a autonomia é outorgada enquanto instrumento de coordenação das relações de trabalho e visa atingir um objetivo econômico de gestão da produção, na busca de inserir no processo de trabalho os elementos que não podem ser prescritos, como a concertação e a mobilização subjetiva. Esta autonomia propicia o aparecimento de estratégias individuais no seio do grupo de trabalho, as relações profissionais reforçam a relação com a empresa e enfraquecem as relações entre os pares. O estudo da relação ao trabalho culmina com uma proposição de tipologia de relação com o trabalho.

Palavras-chave: relação com o trabalho, autonomia outorgada, liberdade, resistência, laço social. 